\title{
International Unit per Milliliter per Microgram per Meter Squared per Day
}

National Cancer Institute

\section{Source}

National Cancer Institute. International Unit per Milliliter per Microgram per Meter

Squared per Day. NCI Thesaurus. Code C119376.

A unit of concentration (biologic activity) equal to one international unit per milliliter, divided by micrograms per meter squared per day. 